\title{
International Journal of Lean Six Sigma \\ Emerald Article: The consequences of Six Sigma on job satisfaction: a study at three companies in Sweden
}

\author{
Karin Schön, Bjarne Bergquist, Bengt Klefsjö
}

\section{Article information:}

To cite this document:

Karin Schön, Bjarne Bergquist, Bengt Klefsjö, (2010),"The consequences of Six Sigma on job satisfaction: a study at three companies in Sweden", International Journal of Lean Six Sigma, Vol. 1 Iss: 2 pp. 99 - 118

Permanent link to this document:

http://dx.doi.org/10.1108/20401461011049494

Downloaded on: 31-05-2012

References: This document contains references to 44 other documents

To copy this document: permissions@emeraldinsight.com

This document has been downloaded 1585 times since 2010. *

\section{Users who downloaded this Article also downloaded: *}

Souraj Salah, Abdur Rahim, Juan A. Carretero, (2010),"The integration of Six Sigma and lean management", International Journal of Lean Six Sigma, Vol. 1 Iss: 3 pp. 249 - 274

http://dx.doi.org/10.1108/20401461011075035

B. Tjahjono, P. Ball, V.I. Vitanov, C. Scorzafave, J. Nogueira, J. Calleja, M. Minguet, L. Narasimha, A. Rivas, A. Srivastava, S. Srivastava, A. Yadav, (2010),"Six Sigma: a literature review", International Journal of Lean Six Sigma, Vol. 1 Iss: 3 pp. 216 -

233 http://dx.doi.org/10.1108/20401461011075017

Sanjit Ray, Prasun Das, (2010),"Six Sigma project selection methodology", International Journal of Lean Six Sigma, Vol. 1 Iss: 4 pp. $293-309$

http://dx.doi.org/10.1108/20401461011096078

Access to this document was granted through an Emerald subscription provided by LULEA UNIVERSITY OF TECHNOLOGY

\section{For Authors:}

If you would like to write for this, or any other Emerald publication, then please use our Emerald for Authors service. Information about how to choose which publication to write for and submission guidelines are available for all. Additional help for authors is available for Emerald subscribers. Please visit www.emeraldinsight.com/authors for more information.

\section{About Emerald www.emeraldinsight.com}

With over forty years' experience, Emerald Group Publishing is a leading independent publisher of global research with impact in business, society, public policy and education. In total, Emerald publishes over 275 journals and more than 130 book series, as well as an extensive range of online products and services. Emerald is both COUNTER 3 and TRANSFER compliant. The organization is a partner of the Committee on Publication Ethics (COPE) and also works with Portico and the LOCKSS initiative for digital archive preservation. 


\title{
The consequences of Six Sigma on job satisfaction: a study at three companies in Sweden
}

\author{
Karin Schön and Bjarne Bergquist \\ Quality Technology and Management, Luleà, Sweden, and \\ Bengt Klefsjö \\ Department of Civil, Mining and Environmental Engineering, \\ Luleå University of Technology, Luleå, Sweden
}

\begin{abstract}
Purpose - The purpose of this paper is to present a study of how Six Sigma influences job satisfaction among employees at three large companies with manufacturing units in Sweden that have used different implementation strategies.

Design/methodology/approach - The study was performed using a survey distributed to those affected by the implementation at the three company sites, including those not directly involved in any Six Sigma activities.

Findings - Employees participating in Six Sigma feel positive changes in many aspects of job satisfaction. The Black Belts (BBs) felt, on the average, positive changes in almost all the tested areas. The largest changes are related to personal and new skill development, influence on work duties and enjoying the work. BBs also feel more recognition from management. Employees not involved in the Six Sigma projects do, on average, also feel positively influenced by Six Sigma, but the tendency is not as clear.

Research limitations/implications - The results constitute a platform for further studies on the relation between Six Sigma applications and job satisfaction due to the different approaches used in the three studied plants.

Practical implications - The positive results should help alleviate concerns of job satisfaction due to implementation of Six Sigma.

Originality/value - The paper fills a knowledge gap concerning the effect of Six Sigma on employees' well being and job satisfaction.
\end{abstract}

Keywords Six sigma, Quality management, Job satisfaction, Sweden

Paper type Research paper

\section{Introduction}

Six Sigma

Six Sigma was created at Motorola in the 1980s. It is by many people seen as a statistically based and process oriented way to reach improvements by reducing variation and measuring the financial output of each driven project (Klefsjö et al., 2006). Six Sigma was not only inspired by quality work in Japan, but also influenced by ideas from Joseph Juran; for instance, the project-by-project approach and the use of capability indices (Juran, 1951; Juran and Godfrey 1999).

The authors would like to express their gratitude for the time and cooperation provided by Anders Månsson and Linda Hinderyd at Ericsson, Peter Cronemyr, and Lise-Lott Gummesson at Siemens and Artur Grzebowski at Volvo Cars. Gratitude is also expressed to all respondents of this study.

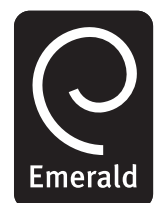

International Journal of Lean Six Sigma

Vol. 1 No. 2, 2010 pp. $99-118$

(C) Emerald Group Publishing Limited 2040-4166 DOI 10.1108/20401461011049494 
IJLSS

1,2

100
Owing to Six Sigma, Motorola managed to reduce their poor-quality costs and decrease variation in many processes. As a result, Motorola became the first recipient of America's Malcolm Baldrige National Quality Award in 1988. Later, many companies, General Electric, Allied Signals, Ford, and Bombardier, to mention a few, have successfully applied Six Sigma. Benefits and financial results of Six Sigma have been documented by, for instance, Harry (1988) and Kwak and Anbari (2006). However, there also are people questioning the financial benefit of the present application of Six Sigma (de Mast, 2006).

Many papers and books have discussed Six Sigma - the concept, its ingredients, its relation to other quality concepts and its benefits; see, for instance, Hendricks and Kelbaugh (1998), Harry and Schroeder (2000), Pande et al. (2000), Klefsjö et al. (2001), Antony and Banuelas (2002), Breyfogle (2003), Schön (2006), Nonthaleerak and Hendry (2006), Klefsjö et al. (2006) and Antony et al. (2007).

Six Sigma is supported by an infrastructure of specialists, often called Master Black Belts (MBBs), Black Belts (BBs), Green Belts (GBs) and Yellow Belts (YBs) - although other "Belts" also occur. MBBs are strategic improvement leaders, often working full time as trainers and improvement leaders. A BB is usually coached by a MBB. Many companies also use GBs, trained members of Six Sigma improvement teams and leaders of small-scale Six Sigma projects. Often, a champion is also appointed among top management, to act as a sponsor and communication channel for the Six Sigma work. These specialists have received education in statistical methodologies and various quality tools - BBs more than Green and Yellow. All the activities, as well as the selection of projects, are usually strongly supported or even determined by top management, which often functions as a critical success factor (Breyfogle, 2003).

Six Sigma consists of both process and people aspects (McAdam and Lafferty, 2004). However, despite the vast literature related to Six Sigma, only a few studies, focusing on understanding the influence on the employees and their work environment have been published (Nonthaleerak and Hendry, 2006).

One survey performed at an American organization (Buch and Tolentino, 2006), concluded that employees felt that Six Sigma supported the receipt of intrinsic rewards, such as, enhanced job satisfaction, new skill development and new job responsibility, and of social rewards. The employees also found more opportunities to interact with colleagues. However, the employees did not rate Six Sigma as aiding their receipt of extrinsic rewards, such as, pay raise or bonus, enhanced job security, and recognition from management. It was also concluded that GBs and BBs thought that there was a stronger link between their involvement in Six Sigma and receiving intrinsic and organizational rewards than did non-participants. However, the study also found that employees, who chose not to participate after receiving GB training, did not expect intrinsic awards, and Buch and Tolentino (2006) suggested that these employees could act as active or passive resistance to the change effort.

Thus, it is important to reach a better understanding of how Six Sigma affects employees in an organization, to devise a better and more precise deployment process, leading to more satisfied employees and a higher success probability of the Six Sigma initiative.

The purpose of this paper is therefore to explore how Six Sigma has influenced job satisfaction among employees in three "Swedish" companies. 
Job satisfaction

Job satisfaction is in this paper understood as "the pleasurable emotional state resulting from the appraisal of one's job as achieving or facilitating the achievement of one's job values" (Locke, 1969).

According to Locke (1969), job satisfaction depends on the perceived relationship between what one wants from the job and what one experiences that the job offers or entails. Rice et al. (1989) also include a discrepancy dimension and argue that job satisfaction partly is determined by the discrepancies resulting from a psychological comparison involving the assessment of current job experiences against some personal standards. For further discussions of job satisfaction, see, for instance, Herzberg et al. (1959), Tsigilis et al. (2004) and Schön (2007).

Job satisfaction is important because it is associated with positive organizational outcomes; see discussion in Kirkman and Shapiro (2001). There is also support for causality between job satisfaction and employee health (Fischer and Sousa-Poza, 2009). Furthermore, the connections between psychologically unsatisfactory work environment and negative effects on employees' health and levels of sickness absence are well documented (Dolbier et al., 2001); Aronsson and Hallsten, 2006). In Sweden, for example, a number of studies have identified successful methodologies for creating a work environment leading to healthy and satisfied employees (Söderlund, 2003; Harnesk et al., 2005; Wreder, 2008; Wreder et al., 2008). Several other studies have also shown the connection between job satisfaction and stress (Dolan, 1987; Tsigilis et al., 2004; Wilson et al., 2004). In other words, employee satisfaction can be boosted by providing good, motivating working conditions that meet the needs of the employees. Accordingly, job satisfaction is affected by many aspects.

There are, however, differences between how people rate their job satisfaction in different countries. A study of 21 countries by Sousa-Pouza and Sousa-Pouza (2000) showed that the highest job satisfaction was obtained in Denmark; the USA was ranked the seventh, Sweden the ninth, Great Britain the 15th and Hungary the 21st.

When discussing Six Sigma, such improvement programs may also be influenced by the national culture. The slower growth of Six Sigma in Europe than in the USA can, for instance, depend on a better cultural fit for Americans (Klefsjö et al., 2008). Trompenaars (1993) used two sliding scales to describe various corporate cultures:

(1) a continuum of status from "equality" to "hierarchy"; and

(2) a continuum of orientation from "person oriented" to "task oriented".

According to Trompenaars (1993), these two scales illustrate four types of corporate cultures:

(1) a "power-oriented" culture;

(2) a "role-oriented" culture;

(3) a "project-oriented" culture; and

(4) a "fulfilment-oriented" culture.

The work by Trompenaars (1993) was analyzed by Crom (2000), who argued that the USA was a very receptive environment for Six Sigma because the corporate culture was typically decentralized (egalitarian) and formal (task oriented). According to Crom (2000), the typical purpose of organizations in the USA was mainly to achieve
Consequences of Six Sigma on job satisfaction

101 


\section{IJLSS 1,2}

\section{2}

defined targets. Crom (2000) also suggested that an organization in Sweden was often conceived as a vehicle through which individuals expressed themselves to realize their full potentials. According to Crom (2000), the appeal of Six Sigma in Sweden was likely to be its potential to enhance personal creativity by minimizing the time spent on avoidable problems.

\section{Company descriptions}

This study includes the three large manufacturing companies Ericsson, Siemens, and Volvo Cars, all with manufacturing units in Sweden. The choice of companies was based on that these three have used different approaches for the implementation process. For more information about their ways to implement Six Sigma, see Schön (2006) for Ericsson and Volvo Cars, and Cronemyr (2007) for Siemens. The companies are briefly described here.

Ericsson. Ericsson is a world-leading provider of telecommunications equipment and related services to mobile and fixed network operators globally. The company was founded in 1876 and has more than 1,000 networks in 140 countries (Ericsson, 2007). The study object of this survey, the Borås site, first encountered Six Sigma in 1996, by being invited to send staff members to a BB training program at ABB. One of the candidates sent into this training has for several years been the "driving force" of the Six Sigma initiative at Ericsson. Thus, the initiative to implement Six Sigma did not come from the executive management, but from a devoted middle manager. Ericsson implements Six Sigma voluntarily, one department at a time, and the initiative slowly propagates through the company (Magnusson et al., 2003; Schön, 2006).

Siemens. Siemens Industrial Turbomachinery AB in Finspång, Sweden, is a part of Siemens AG, one of the world leaders in power supply, transmission, and distribution. Siemens AG employs about 475,000 people in 190 countries worldwide. The local company in Finspång has a history of making turbines for approximately a century under the names of Svenska Turbinaktiebolaget Ljungström, STAL Laval, ASEA STAL, ABB STAL, Alstom Power, and nowadays, Siemens. The Six Sigma approach in Finspång was started by Alstom in 2001 as a limited top-down deployment. When Siemens took over in 2003, the Six Sigma program was restarted with stronger management involvement. The major participants of the Six Sigma program in Finspång have been the Gas Turbine Division (Siemens G) and the Service Division (Siemens S). In the Service Division, the Six Sigma program was integrated with process management and run by the management team while the program in the Gas Turbine Division was run as a separate initiative (Cronemyr, 2007).

Volvo Cars. Volvo was founded as a car manufacturer in Gothenburg, Sweden, in 1927. Later, Volvo started other businesses, such as heavy trucks and construction vehicles. In 1999, the car division, Volvo Cars, was sold and has been wholly owned by Ford Motor Company since then. Volvo Cars mainly produces vital components, such as engines and body components in Sweden, but major plants and production facilities are also located in Belgium, The Netherlands, South Africa, Thailand, and Malaysia. In 2006, Volvo Cars produced about 460,000 cars. The USA is the company's largest market, which in 2005 accounted for 28 percent of the total sales volume. The USA is followed by Sweden (12 percent), Britain (8.6 percent), Germany (7.9 percent), and Italy (4.6 percent). In 2007, the company employed about 24,500 people around the world. About 17,500 of these were working in Sweden. 
Method

\section{Research instrument}

The purpose of this work was to test if the implementation of Six Sigma had effects on the working conditions of those involved in the Six Sigma work, and if those not involved had experienced any consequences from the implementation. A questionnaire was designed to measure how the employees felt that Six Sigma had affected their work situation and job satisfaction. The concept of job satisfaction was then divided into four main categories: comfort, influence, cooperation and fellowship, and personal development. This categorization of job satisfaction was based on the findings from Söderlund (2003), Harnesk et al. (2005), Buch and Tolentino (2006) and Wreder (2008).

Each of the four categories was explored using three to seven questions (Figure 1). The complete questionnaire is presented in Schön (2007).

The respondent was asked to answer each question by selecting one statement among six alternatives. The five main alternatives ranged from "Six Sigma is making a very negative contribution" to "Six Sigma is making a very positive contribution" on the asked matter in that question. The verbal scale was phrased to fit the question and included a middle alternative being a "no change" - answer. The sixth alternative was "I do not know" or "I do not have an opinion". To make the questionnaire simple and easy to fill out, every question (except background questions) started with "I think Six Sigma has contributed to[...]"; see an example of question in Table I.

After an overall question related to how much Six Sigma had influenced the respondent and the questions related to the four categories of personal changes, the respondents were asked four questions on how they felt Six Sigma had influenced their organization. The respondents were also asked to rate their overall experience of Six Sigma. The questionnaire was concluded with an open-ended question with possibilities for any kind of comments on the matter. Except for some background questions, the questionnaire contained 30 questions.

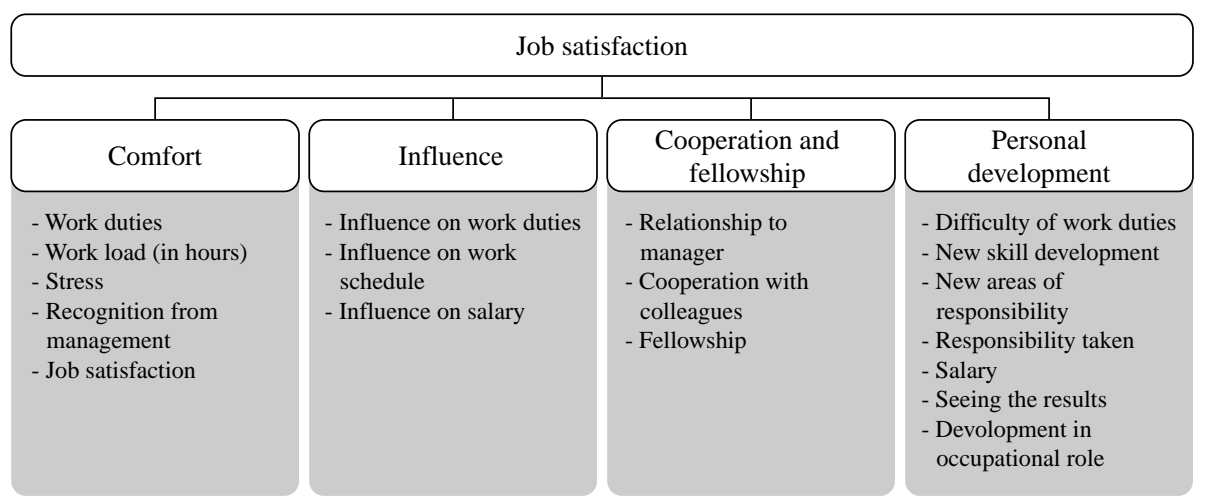

Thanks to SS, the influence I now have over my working tasks is

$\begin{array}{lllll}\text { Much less } & \text { Slightly less } \quad \text { Unchanged } & \text { Slightly more } & \text { Much more } & \text { I do not know }\end{array}$

Consequences of Six Sigma on job satisfaction

103
Figure 1.

Job satisfaction categories used in the questionnaire and the subject of the particular questions

Table I. One example of question in the questionnaire used in the study 


\section{IJLSS \\ 1,2}

104
Sample and data collection

The survey was performed during Spring 2007 at the three manufacturing companies Ericsson, Siemens, and Volvo Cars. At Ericsson, the Borås plant in Sweden was chosen as study object, and the two divisions Siemens S and Siemens G were chosen at the Industrial Turbomachinery plant of Siemens in Finspång, Sweden. The plant at Torslanda just outside Gothenburg was selected at Volvo Cars.

The plants were chosen in cooperation with corporate management and related to the emphasis and application of Six Sigma within the company. We were told to limit the number of questionnaires at all the three companies to reduce work disturbance.

Four groups were targeted at Ericsson and Siemens, namely BBs, GBs, middle managers, and non-participants (i.e. employees not involved in any Six Sigma activities).

Discussions with management at Ericsson and Siemens resulted in a decision to involve $20 \mathrm{BBs}$ (including MBBs), $20 \mathrm{GBs}$ (or similar), 20 middle managers and 40 non-participants. The questionnaires were distributed through our management contacts, who were informed of the importance to distribute them randomly in the different groups. At Siemens, the questionnaires were divided between two divisions, Siemens G and Siemens S, because of their separate Six Sigma initiatives. However, the group of BBs at Siemens $\mathrm{S}$ is smaller than the other BB groups (there were only four), which meant that only 14 BBs were selected at Siemens. The group of non-participants was larger than the other groups, as this group was expected to have a lower response rate. Accordingly, 194 questionnaires were mailed to Ericsson and Siemens and distributed internally.

At Volvo Cars, most middle managers are also GBs, which made separation of these groups difficult. Thus, only BBs, GBs, and non-participants were targeted at this company. At Volvo Cars, we were allowed to involve $40 \mathrm{BBs}, 40 \mathrm{GBs}$, and 80 non-participants. It turned out that seven of the chosen people had left the company or were on long-term leave. Also, 11 people with other roles than BB and GB within Six Sigma were excluded. Therefore, the number of possible respondents at Volvo became 142.

To sum up, 100 questionnaires were distributed at Ericsson, 94 at Siemens, and 142 at the Volvo Car plant. The individual package consisted of the questionnaire itself, a cover letter, and a stamped preaddressed return envelope to the authors of this paper. As response incentive, each respondent was automatically included in a drawing of lottery tickets as well as promised to receive information of the study results. The questionnaire was in Swedish so all respondents were speaking Swedish.

\section{Response rate}

After one reminder, 256 of the totally 336 questionnaires were returned, representing 76 percent response rate. This high response rate was encouraging compared with other studies related to Six Sigma. For example, Buch and Tolentino (2006) reported 34 percent response rate, and Antony et al. (2006) reported 12.5 percent response rate.

When studying the returned questionnaires, we realized that some of the persons in the original category "not involved" in reality had been included as "team members" at Siemens and as White Belts at Ericsson. Therefore, a new category called "team members" was created and some people were moved from the category "not involved" to this new category (Table II).

The Six Sigma structure is somewhat different at Volvo Cars compared to Ericsson and Siemens. Therefore, the analysis has been performed in two phases. In Phase 1, just Ericsson and Siemens are compared since these companies have a similar structure. 
In Phase 2, all the three companies are compared on another level than in the first phase. Tables II and III show the number of returned questionnaires used in the analysis in the two phases.

\section{Analysis}

The data were managed using pivot tables in Microsoft Office Excel 2003, and the statistical analysis was made using Statgraphics Centurion XV.

\section{Results}

In this section, the results obtained from the analysis in the two phases are illustrated and commented upon. Phase 1 is the analysis based on Ericsson and Siemens and Phase 2 consists of a comparison among all three companies. The discussion in both phases is structured according to four parts: the overall influence on the employee; the personal change on job satisfaction according to the four categories; the employee's impression of the influence on the organization; the overall judgment of Six Sigma's influence on the company. After the two phases are discussed, verbal comments to the questions from the three companies are presented and discussed.

\section{Phase 1. Results when comparing Ericsson and Siemens}

The overall influence of Six Sigma on the employee. One of the first questions dealt with to what extent the respondent felt that Six Sigma had changed the respondent's work situation. From Figure 2, we can see, as expected, that the BBs experienced the largest influence and those "not involved" the smallest.

Personal changes. How the respondents at Ericsson and Siemens felt that Six Sigma had affected the four categories of job satisfaction is presented in Table IV.

\begin{tabular}{lccccc}
\hline & Ericsson & Siemens G & Siemens S & Total (Ericsson and Siemens) & Volvo \\
\hline BB & 16 & 9 & 4 & 29 & 32 \\
GB or YB & 16 & 9 & 12 & 37 & 28 \\
Team member & 5 & 3 & 6 & 14 & - \\
Not involved & 16 & 12 & 10 & 38 & - \\
Manager & 16 & 11 & 10 & 37 & 101 \\
Total & 69 & 44 & 42 & 155 & 71 \\
$(\%)$ & 69 & 88 & 84 & 80 &
\end{tabular}

Note: A new category "team member" has been created here

\begin{tabular}{lcccc}
\hline & Ericsson & Siemens G & Siemens S & Volvo Cars \\
\hline BB & 16 & 9 & 4 & 32 \\
GB/YB & 16 & 9 & 12 & 28 \\
Not involved & 16 & 12 & 10 & 41 \\
Total & 48 & 30 & 26 & 101
\end{tabular}

Consequences of Six Sigma on job satisfaction

105 


\section{IJLSS}

1,2

\section{6}

Figure 2.

Responses on how much Six Sigma has affected the respondents' work situation
How much has six sigma affected your work situation?

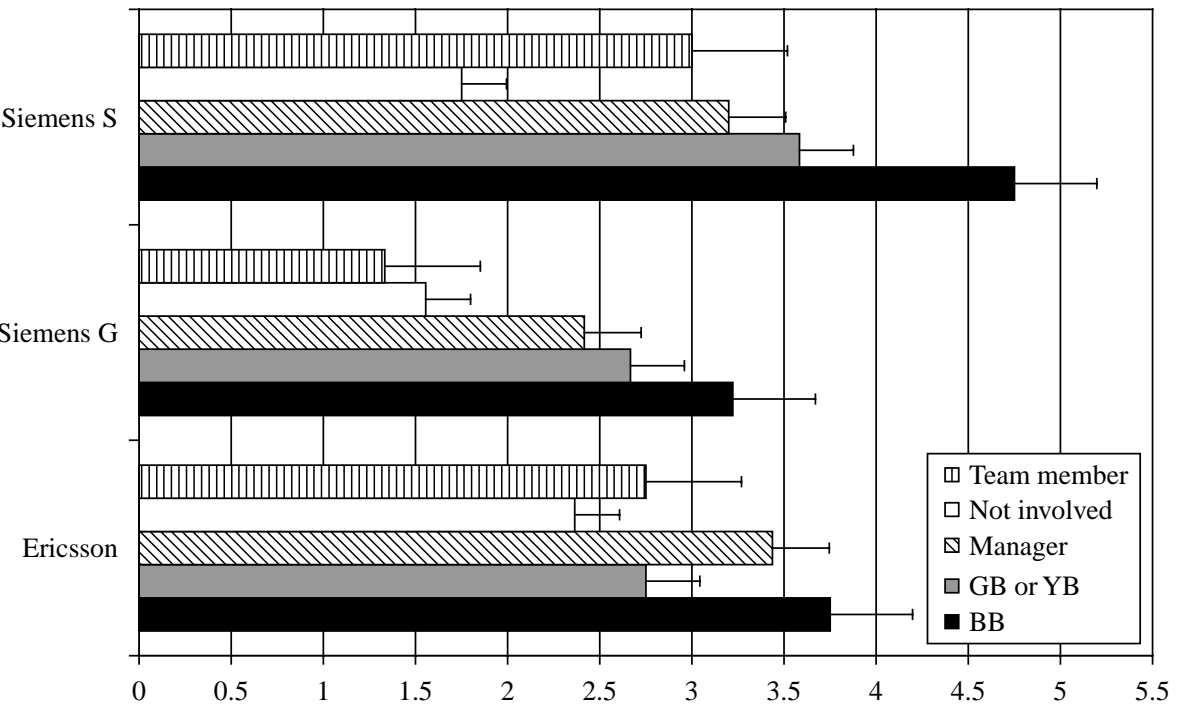

Notes: The endpoints of the filled boxes indicate the locations of the lower and upper quartiles, and the whiskers indicate the location of smallest or largest values, with the exception of an outlying team member response; all respondents were asked how much they felt six sigma had affected their work situation; as shown in the Box-and-Whisker plot, Figure 2, the BBs say that they are most affected and non-participants the least affected; the scale goes from " $1 \frac{1 / 4}{4}$ not affected" to "5 1/4 much affected"

Within the comfort category, answers to three questions indicated positive effects by Six Sigma:

(1) the work duties felt more enjoyable;

(2) the amount of recognition received from management had increased; and

(3) the level of job satisfaction had increased for the participants of Six Sigma.

Regarding workload and stress, there was no significant difference in or between the sample groups. These two questions received a negative mean from both the BB group and the $\mathrm{GB} / \mathrm{YB}$ group. However, the hypothesis, that:

H1. No change has occurred (median $=3$ ), cannot be rejected at 5 percent significance level.

Within the influence category, the respondents rated that their influence on personal work duties had increased. The BBs also felt that their influence on work schedule had increased.

In the third category, cooperation and fellowship, cooperation with colleagues had increased and the fellowship at the workplace had improved according to most participants. The relationship to the employee's manager was only improved for BBs.

The category "Personal development" included questions where the respondents felt positive changes. The only question where the zero hypotheses "no change" could not be rejected was the one related to salary. The outstanding parts of this category were: 


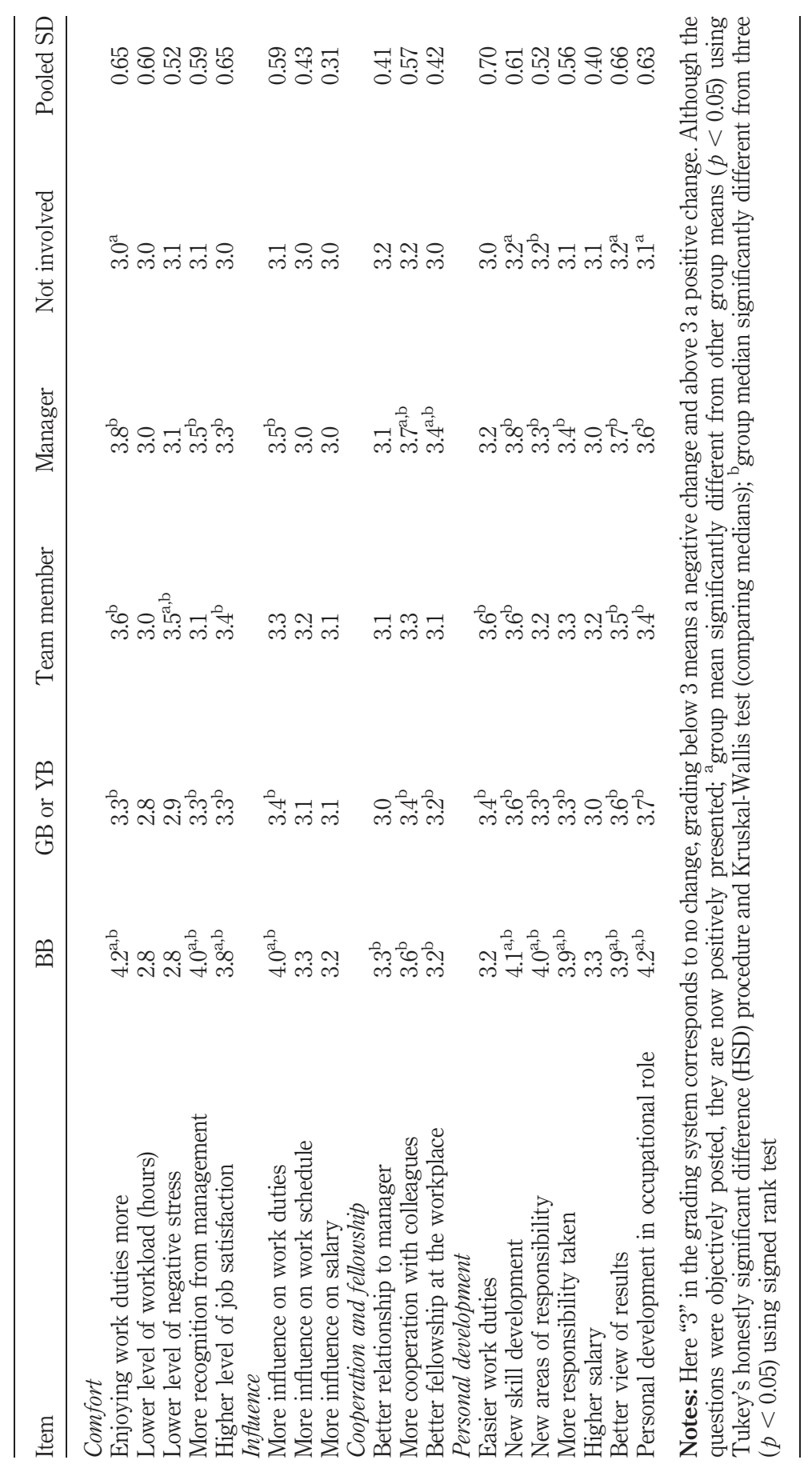

Consequences of Six Sigma on job satisfaction

107

Table IV.

Results (mean values) from "personal changes due to Six Sigma" 
IJLSS
1,2

108

(1) the feelings of new skill development;

(2) the improved view of results; and

(3) the personal development in occupational role.

Observe the small differences between sample groups for these three questions, implying that all participants felt positively affected by Six Sigma on these matters.

Organizational changes. The respondents were also asked to grade how they felt Six Sigma had affected their organization. Table V shows high grading from all five groups in the two companies, with company profits being most improved.

Overall judgment of Six Sigma on the company. The respondents from both Ericsson and Siemens had a positive attitude to Six Sigma (Table V). There is also a significant difference $(p<0.05$; Kruskal-Wallis test) in attitude between Ericsson and the two divisions at Siemens, with the Ericsson respondents being more positive.

\section{Phase 2. Results when comparing all three companies}

In this phase, all the three companies were included in the analysis and compared. The managers and the team members at Ericsson and Siemens were now excluded from the comparison, since these groups were not part of the Volvo Cars survey. Furthermore, the group of team members at Ericsson and Siemens was small and the answers from the managers just slightly differed from those by the GBs, which also motivated this exclusion. In our opinion, the most important target groups were the BBs, GBs/YBs, and non-participants at the three companies.

The overall influence of Six Sigma on the employee. All respondents were asked how much they felt Six Sigma had affected their work situation. As shown in Figure 3, the BBs were most affected and the non-participants the least affected. The scale goes from "1 - not affected" to "5 - much affected".

It is not surprising to see that BBs are most affected by Six Sigma, as they work full time with the Six Sigma projects. Of interest are the results showing that non-participants at Ericsson felt more affected by Six Sigma than what non-participants at the other organizations did. An explanation of this might be that the Ericsson site in Borås has worked with Six Sigma more than ten years and that positive project results have been spread by word of mouth, affecting most people in the organization.

Personal changes. The results of the four categories of job satisfaction when comparing all the three companies are summarized in Table VI.

The overall pattern in Table VI does not change much with Volvo Cars included compared to Table VII. However, the larger sample with more non-participants included has lowered the total scores. The largest positive effects are still found on work duties, recognition from management, influence on work duties, new skill development, new areas of responsibility, better view of results, and especially personal development.

Table V.

Overall judgment of Six Sigma at Ericsson and Siemens

\begin{tabular}{lcccccc}
\hline & BB & GB or YB & Team member & Manager & Not involved & Total \\
\hline Ericsson & 4.4 & 4.1 & 4.0 & 4.8 & 3.6 & 4.2 \\
Siemens G & 3.9 & 3.1 & 3.3 & 3.8 & 3.4 & 3.5 \\
Siemens S & 4.0 & 4.0 & 4.4 & 3.7 & 3.3 & 3.9 \\
Total & 4.2 & 3.9 & 4.0 & 4.2 & 3.5 & 3.9 \\
\hline
\end{tabular}




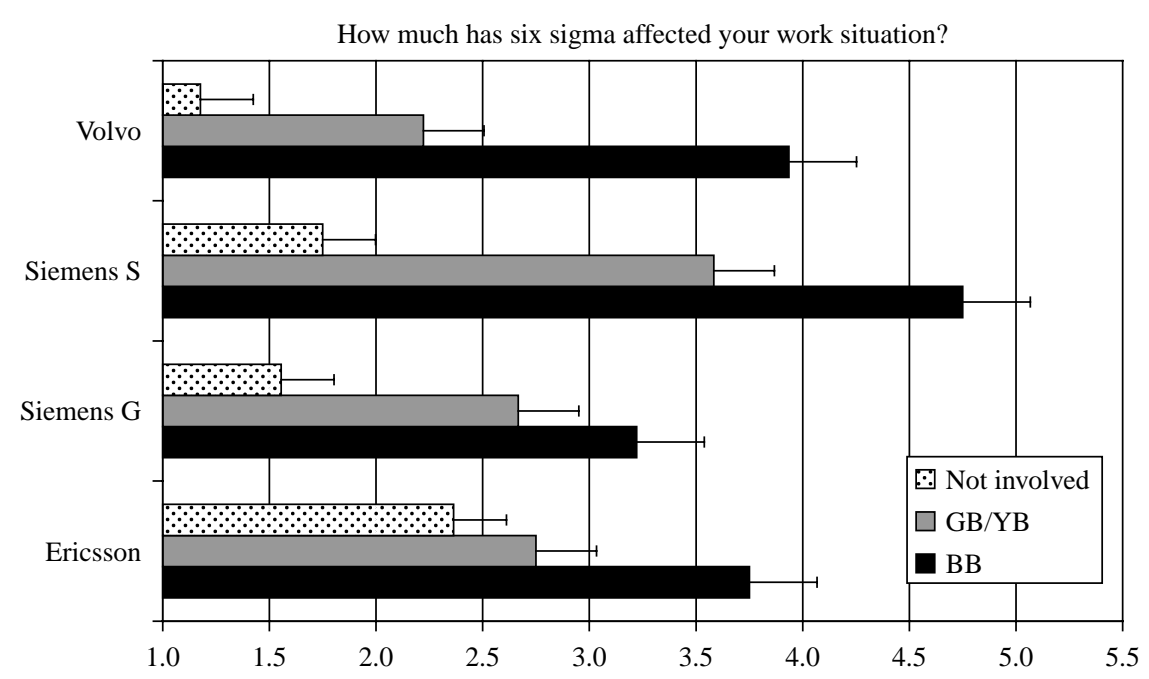

Notes: Here "1" in the grading system corresponds to "not affected" and " 5 " corresponds to "much affected"; error bars indicate standard error
Consequences of Six Sigma on job satisfaction

109

Figure 3.

Responses on how much Six Sigma has affected the respondents' work situation

The two areas with the lowest grading are still workload and stress. Non-participants in Six Sigma were generally not affected. Only one question, "New areas of responsibility", showed a significant difference from 3 . However, it was just barely significant and could therefore be questioned. The same is true of, for example, "Relationship to manager", where BBs showed a significant positive affect at 3.2. We do not wish to speculate on reasons for these small deviations from 3 , since those effects barely are significant.

To illustrate how the results of the different companies followed a similar pattern, diagrams related to some of the questions are presented below and commented upon. The questions illustrated below are those indicating the largest influence on job satisfaction.

The question with the lowest total score proved to be the question on workload (Figure 4). The results indicate that some BBs and GBs felt that they were working more hours because of Six Sigma. For the GBs, the larger workload is easily explained. GBs only work part time with Six Sigma and hence still had their ordinary work duties on the side. In the open-ended question, a few GBs stated that more duties had been put on their shoulders without compensation in other areas. However, the survey results do not indicate why the BBs worked more hours because of Six Sigma.

At Volvo, some of the BBs are so-called "embedded BBs", which means that they only work part time as BBs. At Ericsson, too, many BBs only work part time with Six Sigma, which gives reason to suspect that these BBs are also given new duties without removing old. A speculative explanation for the increased workload of the BBs could therefore be that working as a BB is hard to combine with other work duties. The GBs' work situation needs to be handled more carefully.

Figure 5 shows that BBs and GBs on the average felt that their overall job situation had improved because of Six Sigma, BBs more than GBs. Non-participants at Volvo Cars and Siemens did on the average not seem to feel any change in job satisfaction, while non-participants at Ericsson felt slightly positively affected. Why non-participants at Ericsson seem to feel more satisfied might be traced to the way Six Sigma has 


\section{IJLSS 1,2}

110

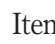

Comfort

Enjoying work duties

Level of workload (hours)

Level of negative stress

Recognition from management

Level of job satisfaction

Influence

Influence on work duties

Influence on work schedule

Influence on salary

Cooperation and fellowship

Relationship to manager

Cooperation with colleagues

Fellowship

Personal development

Easier work duties

New skill development

New areas of responsibility

Responsibility taken

Salary

View of results

Personal development in occupational role

$\mathrm{BB}$

GB or YB

Not involved

Pooled SD

$\begin{array}{ll}4.0^{\mathrm{a}, \mathrm{b}} & 3.3^{\mathrm{b}} \\ 2.7^{\mathrm{a}, \mathrm{b}} & 2.8^{-} \\ 2.9 & 2.9 \\ 3.9^{\mathrm{a}, \mathrm{b}} & 3.3^{\mathrm{b}} \\ 3.8^{\mathrm{a}, \mathrm{b}} & 3.1\end{array}$

3.0

3.0

3.0

$3.1^{\mathrm{a}}$

3.0

$3.0^{\mathrm{a}}$

3.0

3.0

3.1

3.1

3.0

3.0

$3.1^{\mathrm{a}}$

$3.1^{\mathrm{b}}$

3.1

3.0

$3.1^{\mathrm{a}}$

$3.0^{\mathrm{a}}$
0.62

0.54

0.49

0.56

0.59

0.47

0.47

0.33

0.49

0.57

0.35

0.58

0.63

0.53

0.54

0.45

0.59

0.60

\section{Table VI.}

Results (mean values) from "personal changes due to Six Sigma" with Ericsson, Siemens, and Volvo Cars included
Notes: Here " 3 " in the grading system corresponds to no change, grading below 3 means a decrease and above 3 an increase of what was being asked; except for "level of workload" and "level of negative stress", where a grading below 3 represents an increased workload or stress; values below 3 should thus be interpreted as "negative influence" and values above 3 as "positive influence" for all questions; " group mean significantly different from other group means $(p<0.05)$ using Tukey's HSD procedure and Kruskal-Wallis test; ${ }^{b}$ group median significantly different from three $(p<0.05)$ using signed rank test
Table VII.

Results from "organizational changes due to Six Sigma" at Ericsson and Siemens
Item

BB GB or YB Team member Manager Not involved Total

\begin{tabular}{lllllll}
\hline Smoother company operations & 4 & 3.8 & 4.2 & 3.9 & 3.8 & 3.9 \\
Better communication among staff & 3.5 & 3.5 & 3.5 & 3.7 & 3.5 & 3.5 \\
Improved company profits & 4.1 & 3.9 & 4.3 & 3.8 & 3.9 & 4 \\
Improved customer satisfaction & 3.8 & 3.8 & 3.8 & 3.9 & 3.5 & 3.8
\end{tabular}

been implemented. Since Six Sigma at Ericsson is implemented slowly and voluntarily (Schön, 2006), it has a good reputation, influencing also the non-participants. Another reason for their good feeling about Six Sigma might be that they had benefited, somehow, from a Six Sigma project.

For the question about new skill development due to Six Sigma, the pattern is expected (Figure 6). The BBs acquire new skills more often than GBs, and GBs more often than non-participants. The non-participants felt unaffected. It seems, just looking at the diagrams, as if the BBs at Siemens S are much more enthusiastic than BBs at the other companies. Note that the group of BBs at Siemens S only consisted of four people, which means that the individual answers are influential. 


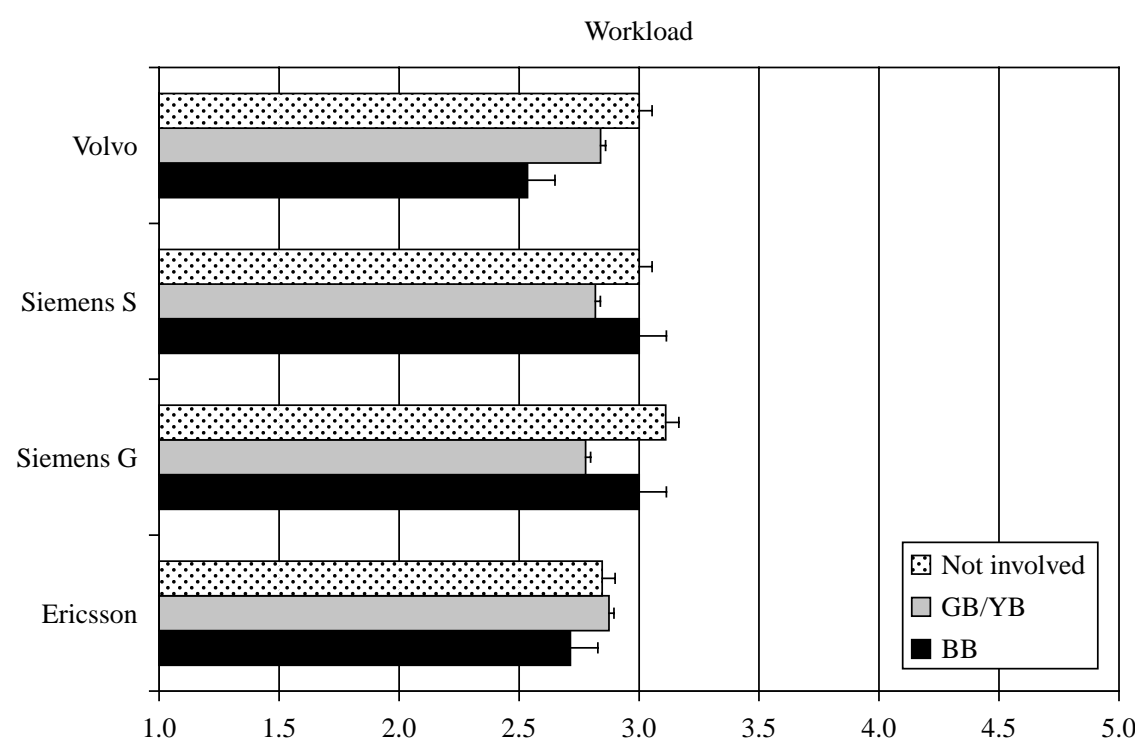

Consequences of Six Sigma on job satisfaction

Notes: Here " 3 " in the grading system corresponds to no change, grading below 3 means an increase (working more hours) and above 3 a decrease (working fewer hours); error bars indicate standard errors (Question 2 on "Comfort")

Figure 4.

Responses on workload

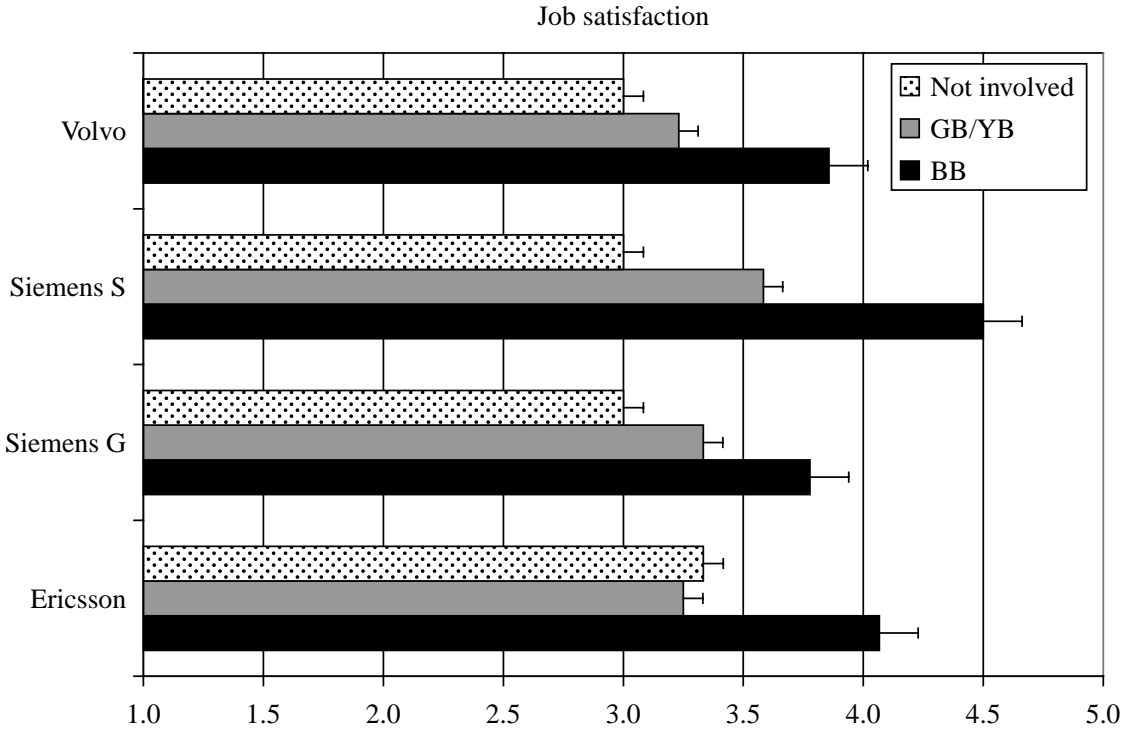

Notes: Here " 3 " in the grading system corresponds to "no change", grading below 3 means a decrease in job satisfaction and above 3 an increase; error bars indicate standard errors (Question 5 on "Comfort")

Figure 5. Responses on overall job satisfaction 


\section{IJLSS \\ 1,2}

112

Figure 6.

Responses on new skill development

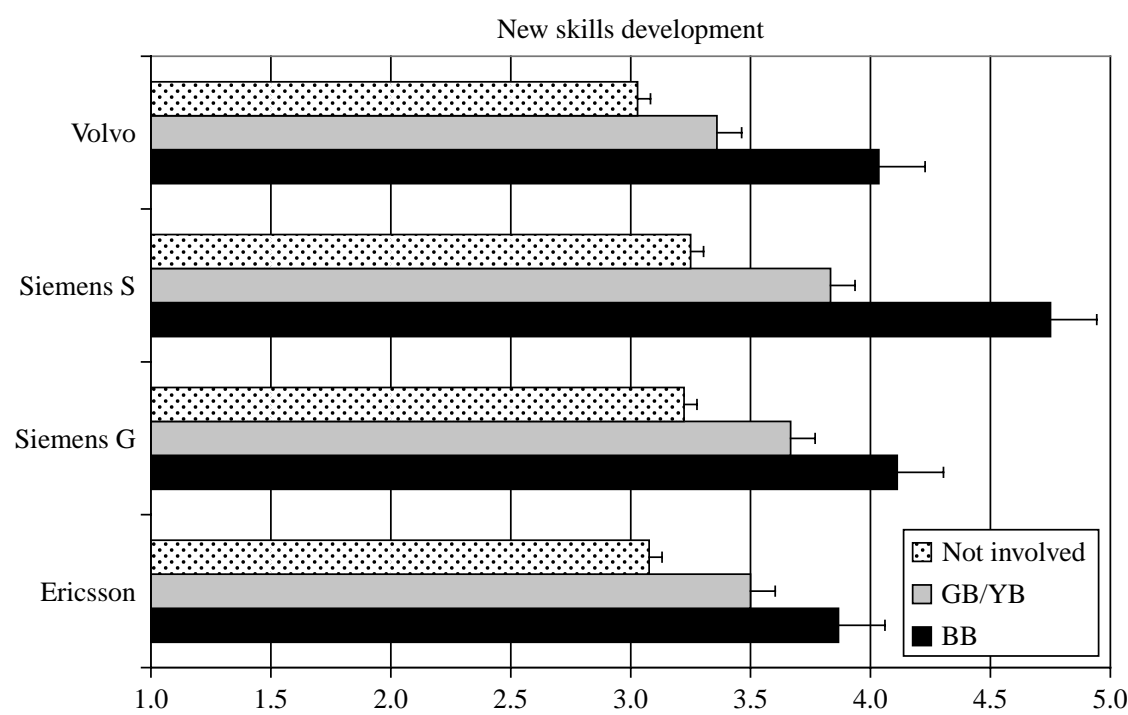

Notes: Here " 3 " in the grading system corresponds to "no change", grading below 3 means a decrease (learning new things more seldom) and above 3 an increase (learning new things more often). Error bars indicate standard errors (Question 2 on "Personal development")

The question on personal development in occupational role was given the highest total score of all questions (Figure 7). As in the previous questions, the BBs were most satisfied followed by GBs. The GBs at Volvo Cars were not as positive as GBs at the other companies regarding this question. One reason for this might be that Volvo Cars was aiming at training everyone to a GB level, and many GBs had, therefore, gone through the training program without further practicing of Six Sigma. It seems natural that people highly involved in projects have experienced a larger increase in developing the occupational role than people that had received training but had not used it in practice.

Organizational changes. The experienced changes on their organization of the four categories are summarized in Table VIII. Many saw the Six Sigma effort aiding the operations, improving customer satisfaction, and ultimately leading to improved profits. Furthermore, many felt that the program had led to better communication amongst the staff. Again, a correlation between the degree of involvement and the response grades could be seen, with those most involved having seen most positive changes because of Six Sigma.

\section{Overall judgment of Six Sigma on the company}

The respondents from all the three companies had a positive attitude to the influence of Six Sigma on their company (Table IX). There is also a significant difference $(p<0.05$; Kruskal-Wallis test) in attitude between Ericsson and the other plants, with the Ericsson respondents being more positive.

Despite the feeling of working more hours, the overall grading of Six Sigma's influence on the company was relatively high. Interestingly, some of the so-far unaffected non-participants seemed to have a positive view of the Six Sigma influence on the company (Table IX). Here again, the non-participants at Ericsson were the most positive, probably caused by pride in producing good results and the attention this had resulted in. 


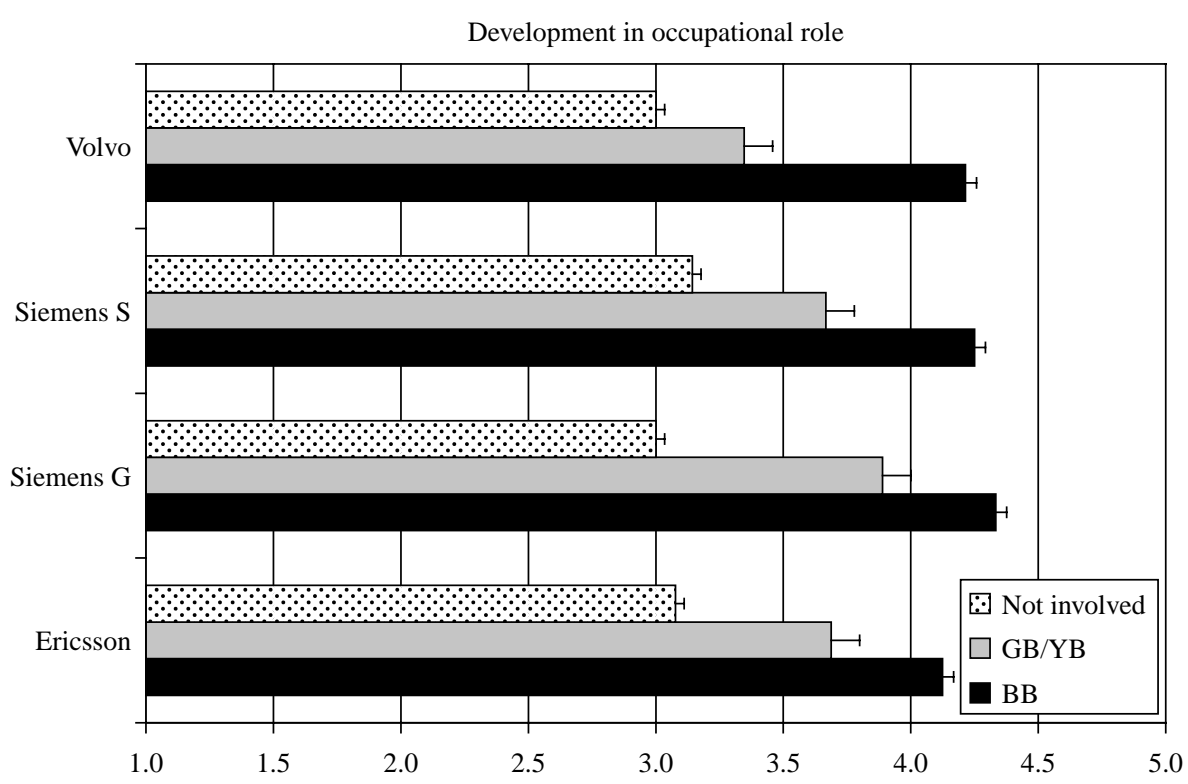

Notes: Here " 3 " in the grading system corresponds to "no change", grading below 3 means a decrease (less development) and above 3 an increase (more development). Error bars indicate standard errors (Question 7 on "Personal development")

\begin{tabular}{lcccc}
\hline Item & BB & GB or YB & Not involved & Total \\
\hline Smoother company operations & 3.8 & 3.6 & 3.5 & 3.6 \\
Better communication among staff & 3.4 & 3.4 & 3.2 & 3.4 \\
Improved company profits & 3.9 & 3.8 & 3.6 & 3.8 \\
Improved customer satisfaction & 3.9 & 3.7 & 3.3 & 3.7
\end{tabular}

Consequences of Six Sigma on job satisfaction

Figure 7.

Responses on personal development in occupational role

Table VIII. Averaged results all companies regarding "organizational changes due to Six Sigma"

\begin{tabular}{lcccrr}
\hline & BB & GB or YB & Not involved & Total & \\
\hline Ericsson & 4.4 & 4.1 & 3.6 & 4.1 & 3.6 \\
Siemens G & 3.8 & 3.4 & 3.4 & 3.8 & Overall judgement of the \\
Siemens S & 4.0 & 4.0 & 3.2 & 3.6 & Six Sigma influence on \\
Volvo & 4.0 & 3.6 & 3.2 & 3.7 & the company \\
Total & 4.0 & 3.8 & & & \\
\hline
\end{tabular}

Overall, the participants and non-participants at Ericsson were the most positive of the Six Sigma work, which might indicate that the Ericsson way of implementing Six Sigma, from the middle and out to only interested sites and departments, had been easy for the employees to accept and even embrace (Schön, 2006).

Comments from respondents

From the open-ended question, 74 comments were collected (about 20 each from Ericsson and Siemens and about 30 from Volvo). Here the respondents were asked 


\section{IJLSS}

1,2

\section{4}

to comment freely on the Six Sigma work or anything else regarding the questionnaire. These comments were first sorted under three major headings: positive, negative, and others. Similar comments were then grouped together and all comments analyzed. Some of the comments are presented below and the numbers within brackets correspond to the number of similar comments:

- "Six Sigma is nothing new, but the structure and framework makes it more legible than other improvement methodologies. People speak the same language" (3).

- "As a technician, I get better data from production".

- "I think the company benefits from structured improvement work. If it is Six Sigma or something else is not really important" (2).

- "Six Sigma works well as a toolbox for standardizing improvements. The most important lesson learned is to actually measure and find causes of problems".

- "We have felt positive effects where Six Sigma has high priority".

- "The most important is that all the company works with Six Sigma and that is a long-term investment”.

- "Positive learning is created when you can see how much the improvement has given".

- "The most important thing about the Six Sigma work is that the company invests in the problem solvers. That gives results of course".

- "The Six Sigma investment has lead to development of competence in the form of BBs to solve difficult problems".

The negative comments were divided into five subgroups:

(1) negative to how it is applied at their company (11);

(2) negative to the methodology as such (4);

(3) not for everyone (4);

(4) increase in workload (2); and

(5) too little training and revisions (2).

The respondents who were negative to the Six Sigma application at Ericsson felt that people trust the tools without critically checking the input and one respondent argued that people were still not good at completing the control phase. The main criticism at Siemens concerned wrongly selected projects, results not being implemented sufficiently, not enough management commitment, and risks of sub-optimizations. The respondents who were negative to Six Sigma as such were found in both companies and had the following motivations: "too complicated and time consuming", "overly administered", and "many people do not know how and why they do things in a certain way". A few comments addressed that Six Sigma was only for a limited group of people. They advocate more participation by everyone within Six Sigma. The comments on increased workload came from part-time participants at Siemens G, and described Six Sigma duties as an addition to the ordinary workload, without compensations in other areas. A couple of respondents at Ericsson felt that more training within the company was needed, teaching Six Sigma to a broader audience and keeping the knowledge up to date. 
Conclusions and discussion

The purpose of this study was to explore how Six Sigma influences job satisfaction among employees in the three "Swedish" companies Ericsson, Siemens, and Volvo Cars. This has been accomplished by using a questionnaire in which most questions were designed to measure the four chosen categories of job satisfaction shown in Figure 1.

As a summary, we conclude that those involved in the Six Sigma improvement work felt positively affected by Six Sigma in most aspects used in the survey. The BBs give the highest grades to work duties, recognition from management, enhanced job satisfaction, influence on work duties, new skill development, new areas of responsibility, responsibility taken, better view of results and personal development in occupational role. The GB/YBs have as top three: new skill development, better view of results and personal development in occupational role. Team members have not been affected in as many areas as BBs and GB/YBs, but are positive to work duties, new skill development, and having a better view of results. Managers express, above all, more enjoyable work duties, more cooperating with colleagues, learning new things, seeing results and developing their occupational role. The only exceptions from the positive responses are the feeling of working more hours and experiencing a higher level of stress, indicated by some of the BBs and GB/YBs. Although the change was not significant at 5 percent significance level, it is still an indication worth taking seriously, since it was commented upon in the open question by several respondents.

According to the questionnaire, "non-participants" of Six Sigma feel that they have not been affected much by Six Sigma. It might beforehand be assumed that those "not included" would show some kind of dissatisfaction due to a feeling of being "outsiders". Interestingly, this investigation does not support that assumption.

As in the study by Buch and Tolentino (2006), we can see that participants of Six Sigma feel more positively rewarded than non-participants. Another resemblance with the study by Buch and Tolentino (2006) is the feeling that Six Sigma improves employees' intrinsic awards, such as, new skill development, clear view of results, and enjoying work duties. However, extrinsic rewards were not found affected by Six Sigma in the study by Buch and Tolentino (2006). In particular, the respondents of the studied company did not see Six Sigma aiding their recognition from management, which have been claimed to be a powerful Six Sigma motivational factor (Larsson, 2003). This study shows positive changes of recognition from management for $\mathrm{BBs}, \mathrm{GB} / \mathrm{YBs}$, and the middle managers.

On the question how the organization has been affected by Six Sigma (Tables V and VI), positive results were obtained from both participants and non-participants. The positive results are likely to be a result of successful work to pass organizational rewards on to employees on the company level. This overall judgment of Six Sigma is probably connected to these organizational rewards. The overall judgment differs between the three companies in the study. The Ericsson employees are more positive to Six Sigma than employees at Siemens. Ericsson has been pursuing the initiative carefully for a longer time and has never forced Six Sigma on anyone. At Siemens, there are differences in the perception of Six Sigma, between Divisions G and S. See Schön (2006) and Cronemyr (2007) for the implementation strategies used.

Of course, there are other differences between the two Siemens divisions than how Six Sigma was launched at the two Siemens divisions, but we argue that their differing implementation strategies have affected job satisfaction. The strategy of having the Six Sigma program run by the management team and having the program integrated
Consequences of Six Sigma on job satisfaction

115 
IJLSS

1,2

116

with process management as the case at Siemens Division S, seems more fruitful for job satisfaction than running the program as a separate initiative. The conclusion that the difference seen in job satisfaction could depend on the different Six Sigma implementation strategies, and full and honest management commitment at Siemens Division S is coherent with management and Six Sigma literature (Harry and Schroeder, 2000).

Although the result from the multiple-choice questions, with its tables and statistics, tells a positive story of how Six Sigma has influenced the employees, the comments in the open question partly indicate another story. Not dismissing the results of the study, one still needs to reflect on the outcome here. There are three plausible explanations of this deviation. First, maybe most unsatisfied employees expressed their frustration in words, while most satisfied employees chose not to comment. The second explanation is the general tendency to use the positive side of the scale in a multiple-choice questionnaire like this (Söderlund, 1997). Third, there is a general recognition that close-ended questions will have lower validity and reliability than open-ended questions (Krosnick, 1999).

However, the negative comments did not come, as one might think, from non-participants only. On the contrary, they were often delivered from all groups of employees included in the study. The only visible pattern detected, was between the three studied companies. There were fewer negative comments from Ericsson, which might be explained by this company's empathetic and voluntary way of running the program. The same pattern was seen in the overall judgment of Six Sigma, presented in Table IX.

As a summary, we conclude that Six Sigma seems to have had a positive influence on job satisfaction for most of participants in the Six Sigma work. The most positively affected element was the personal development, an important building block of a person's job satisfaction (Harnesk et al., 2005). The respondents highlighted feelings of learning new things, seeing results more easily and feelings of overall development in their occupational roles. Other apparent results were the respondents' opinion of enjoying, and having more influence on work duties due to Six Sigma.

Finally, some comments on cultural differences should be made. As discussed earlier, how people rate their job satisfaction differs among different countries (Sousa-Pouza and Sousa-Pouza, 2000). This might have influenced the base level of job satisfaction obtained in this study. Furthermore, the Swedish corporate "participative" culture, as discussed by Crom (2000) and Gowen (2002), as well as the approaches used in the studied companies (Schön, 2006) might influence the results. So to sum up, it is not obvious that the results presented here can be transferred to other national or business cultures.

\section{References}

Antony, J. and Banuelas, R. (2002), "Key ingredients for the effective implementation of six sigma programme”, Measuring Business Excellence, Vol. 6 No. 4, pp. 20-7.

Antony, J., Antony, F. and Kumar, M. (2006), "Six sigma in service organizations”, International Journal of Quality \& Reliability Management, Vol. 24 No. 3, pp. 294-311.

Antony, J., Antony, F., Kumar, M. and Cho, R. (2007), "Six sigma in service organizations: benefits, challenges, difficulties, common myths and success factors", International Journal of Quality \& Reliability Management, Vol. 24 Nos 2/3, pp. 294-311.

Aronsson, G. and Hallsten, L. (2006), Stress, psykisk ohälsa och sjukskriuningar, Arbetslivsinstitutet, available at: www.arbetslivsinstitutet.se/ (in Swedish).

Breyfogle, F.W. III (2003), Implementing Six Sigma, Wiley, Hoboken, NJ. 
Buch, K. and Tolentino, A. (2006), "Employee perception of the rewards associated with six sigma", Journal of Organizational Change Management, Vol. 19 No. 3, pp. 356-64.

Crom, S. (2000), "Implementing Six Sigma in Europe: a cross-cultural perspective", Quality Progress, Vol. 33 No. 10, pp. 73-5.

Cronemyr, P. (2007), "Six sigma management", doctoral thesis, Division of Quality Sciences, Chalmers University of Technology, Gothenburg.

de Mast, J. (2006), "Six sigma and competitive advantage”, Total Quality Management, Vol. 17 No. 4, pp. 455-64.

Dolan, N. (1987), "The relationship between burnout and job satisfaction in nurses", Journal of Advanced Nursing, Vol. 12 No. 1, pp. 3-12.

Dolbier, C., Soderstrom, M. and Steinhardt, M.A. (2001), "The relationships between self-leadership and enhanced psychological health, and work outcomes", The Journal of Psychology, Vol. 135 No. 5, pp. 469-85.

Ericsson (2007), “Corporate information”, available at: www.ericsson.com/ericsson/corpinfo/ (accessed March 27, 2007).

Fischer, J.A.V. and Sousa-Poza, A. (2009), "Does job satisfaction improve the health of workers? New evidence using panel data and objective measures of health", Health Economics, Vol. 18 No. 1, pp. 71-89.

Gowen, C.R. (2002), "How to implement Six Sigma for maximum benefit", Six Sigma Forum Magazine, Vol. 1 No. 2, pp. 27-31.

Harnesk, R., Schön, K. and Bäckström, I. (2005), "How successful Swedish organizations achieve sustainable health", International Journal of Management Practice, Vol. 1 No. 3, pp. 233-50.

Harry, M. (1988), "Six sigma: a breakthrough strategy for profitability", Quality Progress, Vol. 31, pp. 60-4.

Harry, M. and Schroeder, R. (2000), Six Sigma: The Breakthrough Management Strategy Revolutionising the World's Top Corporations, Doubleday Currency, New York, NY.

Hendricks, C.A. and Kelbaugh, R.L. (1998), "Implementing Six Sigma at GE", Quality and Participation, Vol. 21 No. 4, pp. 48-53.

Herzberg, F., Mausner, B. and Snyderman, B. (1959), The Motivation to Work, Wiley, New York, NY. Juran, J.M. (1951), Quality Control Handbook, 1st ed., McGraw-Hill, New York, NY.

Juran, J.M. and Godfrey, B. (1999), Juran's Quality Handbook, 5th ed., McGraw-Hill, New York, NY.

Kirkman, B.L. and Shapiro, D.L. (2001), "The impact of cultural values on job satisfaction and organizational commitment in self-managing work teams: the mediating role of employee resistance", Academy of Management Journal, Vol. 44 No. 3, pp. 557-69.

Klefsjö, B., Bergquist, B. and Edgeman, R.L. (2006), "Six sigma and total quality management: different day, same soup?", International Journal of Six Sigma and Competitive Advantage, Vol. 2 No. 2, pp. 162-78.

Klefsjö, B., Bergquist, B. and Garvare, R. (2008), "Quality management and business excellence, customers and stakeholders - do we agree on what we are talking about, and does it matter?", The TQM Journal, Vol. 20 No. 2, pp. 120-9.

Klefsjö, B., Wiklund, H. and Edgeman, R. (2001), "Six sigma seen as a methodology for total quality management”, Measuring Business Excellence, Vol. 5 No. 1, pp. 31-5.

Krosnick, J.A. (1999), "Survey research”, Annual Review of Psychology, Vol. 50 No. 1, pp. 537-67.

Kwak, Y.H. and Anbari, F.T. (2006), "Benefits, obstacles, and future of six sigma approach", Technovation, Vol. 26, pp. 708-15.
Consequences of Six Sigma on job satisfaction 


\section{IJLSS}

1,2

118

Larsson, A. (2003), Demystifying Six Sigma, AMACOM, New York, NY.

Locke, E.A. (1969), "What is job satisfaction”, Organizational Behavior and Human Performance, Vol. 4 No. 2, pp. 309-36.

McAdam, R. and Lafferty, B. (2004), "A multilevel case study critique of six sigma: statistical control or strategic change?”, International Journal of Operations \& Production Management, Vol. 24 No. 5, pp. 530-49.

Magnusson, K., Kroslid, D. and Bergman, B. (2003), Six Sigma - The Pragmatic Approach, Studentlitteratur, Lund.

Nonthaleerak, P. and Hendry, L.C. (2006), "Six sigma: literature review and key future research areas", International Journal of Six Sigma and Competitive Advantage, Vol. 2 No. 2, pp. 105-61.

Pande, P.S., Neuman, R.P. and Cavanagh, R.R. (2000), The Six Sigma Way: How GE, Motorola and Other Top Companies are Honing Their Performance, McGraw-Hill, New York, NY.

Rice, R.W., Bennet, D.E. and McFarlin, D.B. (1989), "Standards of comparison and job satisfaction”, Journal of Applied Psychology, Vol. 74 No. 4, pp. 591-8.

Schön, K. (2006), "Ways of implementing six sigma in a non-American culture", International Journal of Six Sigma and Competitive Advantage, Vol. 2 No. 4, pp. 404-28.

Schön, K. (2007), "Job satisfaction, six sigma improvement work and the interconnection between the two", Licentiate thesis, Division of Quality and Environmental Management, Luleå University of Technology, Luleå.

Söderlund, B. (2003), "På spaning efter friskfaktorer", in Abrahamsson, K., Bradley, G., Brytting, T., Eriksson, T., Forslin, J., Miller, M., Söderlund, B. and Trollestad, C. (Eds), PREVENT Arbetsmiljö i samverkan Svenskt Näringsliv, Chapter in Friskfaktorer i arbetslivet, LO \& PTK, Stockholm, pp. 268-82 (in Swedish).

Söderlund, M. (1997), Den nöjda kunden, Liber, Malmö (in Swedish).

Sousa-Pouza, A. and Sousa-Pouza, A.A. (2000), "Well-being at work: a cross-national analysis of the levels and determinants of job satisfaction”, Journal of Socio-Economics, Vol. 29 No. 6, pp. $517-38$.

Trompenaars, F. (1993), Riding the Waves of Culture: Understanding Cultural Diversity in Business, Nicholas Brealey Publishing, London.

Tsigilis, N., Koustelios, A. and Togia, A. (2004), "Multivariate relationship and discriminant validity between job satisfaction and burnout", Journal of Managerial Psychology, Vol. 19 No. 7, pp. 666-75.

Wilson, M.G., Dejoy, D.M., Vandenberg, R.J., Richardson, H.A. and McGrath, A.L. (2004), "Work characteristics and employee health and well-being: test of a model of healthy work organization", Journal of Occupational \& Organizational Psychology, Vol. 77, pp. 565-88.

Wreder, A. (2008), "How leadership and new technology influence the work environment", doctoral thesis, Division of Quality and Environmental Management, Luleå University of Technology, Luleå.

Wreder, A., Gustavsson, M. and Klefsjö, B. (2008), "Management for sustainable health: a TQM-inspired model based on experiences taken from successful Swedish organizations", International Journal of Quality \& Reliability Management, Vol. 25 No. 6, pp. 561-84.

\section{Corresponding author}

Bengt Klefsjö can be contacted at: bengt.klefsjo@1tu.se

To purchase reprints of this article please e-mail: reprints@emeraldinsight.com Or visit our web site for further details: www.emeraldinsight.com/reprints 